\title{
editorial
}

\section{Where's the beef?}

\footnotetext{
S:
} ome of you may remember the 1984 US presidential campaign in which Walter Mondale used this slogan to ridicule his rival for the Democratic Party's presidential election candidate. "Where's the beef?" was M ondale's answer to Senator Gary Hart's proposal to cut taxes, improve social welfare and increase access to health and education, all at the same time. It effectively questioned these plans, which were like a beefless hamburger-empty and with no substance-with no chance of being realized given the US budget deficits at the time.

Here in Europe, it is time that we scientists ask our politicians the same question: Where's the beef? As I write this editorial in early July, after the discussions on the next European Union (EU) multi-annual budget failed, I cannot help but feel duped as a scientist. This view is shared by thousands of colleagues who have signed a petition calling for an increase in the EU 's budget for research (www.embo.org).

Let me remind you of all the pompous proposals our political leaders have made over the past few years before I explain how the beef disappeared. In 2000, the heads of the EU Member States met in Lisbon, and concluded that Europe should become the world's leading knowledge-based economy. Bravo! They earned further applause when they met again in 2002 in Barcelona, and concluded that by 2010 the EU as a whole should spend $3 \%$ of its GDP on research and development to reach that laudable goal. Cheers to that! Following up on this proposal, the European Commission (EC) produced a steady stream of documents showing that this new knowledge-based economy needs more skilled personnel, that European universities need more attention and support, that the career prospects of scientists need to be improved, and that Europe should improve its research infrastructures. The national research councils responded positively, and scientific research soon became an important topic in European political circles. The EC accepted and championed the scientists' arguments for a special Europe-wide programme to support all areas of basic research, which was eventually embraced by the European ministers of research. The concept of a European Research Council (ERC) was accepted, even if some details still needed refinement. Even a new term-'frontier research'-was coined to characterize the work that needs to be supported by the ERC.

These proposals were all on the table when the EC announced its plans for the next sevenyear Framework Programme for research. They requested a doubling of research funds and proposed a forward-looking plan that included the establishment of an ERC supported by a significant sum of money and a good balance with the existing Framework Programme. When reading the budget proposal, I felt that, at last, the scientific community's arguments were in harmony with the aspirations of our political leaders.

It now seems that it was a cruel deception. M ost of the leaders who promoted the Lisbon and Barcelona declarations have insisted on an EU budget that would apparently continue to subsidize each European cow with about $€ 2$ per day for years to come. Overall, support for European agriculture would comprise almost $45 \%$ of the total EU funds, as was agreed by the Member States two years ago. There is also a need to support the new M ember States financially-and some members of the original cast-to improve their economic infrastructure. No doubt the money spent on these schemes, such as the Structural Funds, has in many cases been a good investment. Ireland is a prime example, as the EU 's support has triggered an impressive economic growth in recent years. The problem, however, is that these funds, together with the farmers' bounty, add up to more than $90 \%$ of the EU 's budget. So, where should research funds come from?

There seemed to be a clever solution: increase the total budget to allow for a doubling of the research funds. By increasing the national contributions from the current value of $1 \%$ to $1.24 \%$ of the GDP, the EU could still meet its promises. But the countries that had previously agreed to invest more into research suddenly backed away. The budget discussions eventually failed because some members were not willing to increase their share, which would have predominantly benefited research activities. A part from anything else, it says a lot about the real meaning of the EU if it collectively struggles to invest $10 \%$ of its budget into the future, while giving multiples of this amount to a dwindling number of farmers.

W hat normally happens when the money in the kitty does not add up to the household needs? Luxury activities are stopped. So what did the heads of state put up for consideration? Chop the research budget, question the need for an ERC, or give it a token amount for the sake of appearances. This proposal, if implemented, would mean that the beef had been stolen. It means that essential investments in the future of the continent can wait, while the producers of real beef continue to graze luxuriously from the trough of European taxes.

The final scene of this potential tragedy has not yet been written. But it is likely that European leaders will settle for a compromise that again ignores the need to invest in the future by continuing agricultural subsidies at the expense of research, showing that they put local populism before strategic thinkingin short, that they squander our future. Policies should recognize today's societal needs and should reflect these in the distribution of funds. But that does not seem to be happening. Instead, a predictable variation of the current flawed proposals will emerge. No doubt there will be a standard announcement that, after exhaustive discussions, the heads of state have reached an agreement. They will gather to smile for the cameras and declare that it was a good day for European citizens. But Europeans will have lost out to a shamefully weak and backward-looking decision.

\section{FrankGannon}

doi:10.1038/sj.embor.7400492 